\title{
Commentary on Using Client-Centered Psychotherapy Embedded Within A Pluralistic Integrative Approach to Help a Client With Executive Dysfunction: The Case of "Judith"
}

\section{Providing Psychotherapy to People with Neuropsychological Impairment: Complexities and Issues Raised by the Case of 'Judith'}

\author{
NIGEL S. KING ${ }^{\text {a,b }}$ \\ ${ }^{\mathrm{a}}$ University of Oxford, Oxford, England \\ ${ }^{\mathrm{b}}$ Correspondence regarding this article should be addressed to Nigel King, Oxford Institute of Clinical Psychology \\ Training, Isis Education Centre, Warneford Hospital, Oxford, OX3 7JX, UK \\ Email:nigel.king@hmc.ox.ac.uk
}

\begin{abstract}
Ward and Hogan (2015) present a case study of 'Judith" where a combination of client-centered psychotherapy, cognitive rehabilitation and social support result in very positive outcomes despite neuropsychological impairments being present and these posing challenges to the intervention. The case study highlights a number of very important issues when providing psychotherapy to clients with cognitive impairments. These include: 1) the common requirement that issues of self identity are explored; 2) the common need for adaptations to be made to the delivery of psychotherapy to mitigate against the effects of cognitive impairments on psychological interventions; 3 ) the need for specialist neuropsychological rehabilitation services to be available to such clients in the long-term and for specialist neuropsychological supervision to be available to clinicians working psychotherapeutically in this area; and 4) the demonstration that emotional growth and positive psychotherapeutic results are possible even when neuropsychological challenges are present. The extent to which these important issues are fully demonstrated by the case of Judith is limited in three main ways: a) there being some lack of clarity regarding the severity of the head injury sustained; b) there being a lack of psychometric data to confirm the type and severity of the cognitive impairments present; and c) there being some ambiguity regarding the relative contribution of organic and psychological factors to Judith's neuropsychological problems.
\end{abstract}

Key words: client-centered psychotherapy; neuropsychological impairment; head injury; clinical case study; case study

The case of "Judith" presented by Ward and Hogan (2015) is a very engaging case study in which the combination of client-centered psychotherapy, cognitive rehabilitation and the reintroduction of social supports into Judith's life resulted in very positive outcomes. The authors helpfully reflect on the relative potency of each of these factors, and it is noteworthy that the clinically significant change occurred only after the cognitive-rehabilitation and social support 
N. King

Complexities and Issues Raised by the Case of "Judith"

Pragmatic Case Studies in Psychotherapy, http://pcsp.libraries.rutgers.edu

Volume 11, Module 1, Article 2, pp. 21-25, 03-01-15 [copyright by author]

elements were added to the intervention (according to the outcome measures). This suggests that these were crucial components in the positive change seen in Judith.

The case also raises fascinating questions about the mechanisms by which insightoriented approaches to psychotherapy might elicit positive changes in clients where executive deficits appear to dramatically impair these abilities, but where self-awareness and reflection appear to be key mechanisms of change. Other questions in this vein might also include the potential for cognitive rehabilitation strategies to manifest as safety behaviors within a cognitive behavioral framework of working, leading to a reduction in the effectiveness of such a treatment modality in this type of case. For example, a diary might be used to minimize memory failures but could become a safety behavior that helps a client to avoid confronting maladaptive cognitions around not succeeding or the likelihood of it occurring in the first place (Potter \& Brown, 2012).

\section{PSYCHOTHERAPY WITH INDIVIDUALS WITH SEVERE NEUROLOGICAL IMPAIRMENT}

Ward and Hogan's case study also raises a number of very important issues relevant to undertaking psychotherapeutic work with people with severe neurological impairment. First it demonstrates how interventions in these circumstances often involve exploring with the client fundamental questions about changed personal identity and how they can redefine and accept themselves as being a "different person” (Gracey, Palmer, \& Ross, 2008). Client-centered psychotherapy and other related approaches clearly have a great deal to offer in this area.

Second the case highlights the well-documented difficulties that can arise when delivering psychotherapeutic interventions to clients with significant neuropsychological deficits (Tyerman \& King, 2012; Whitehouse, 1994). In this instance executive impairments are reported as the most prominent difficulties, and the study describes some of the adaptations required to address the impact of these on the psychological intervention.

Third, it demonstrates the need for specialist psychotherapeutic services to be available in the long-term for patients with neurological disorders. Judith found herself in the not uncommon position for people with acquired brain injury of being dependent on the "scaffolding" of families, friends and services to maintain her practical day-to-day functioning. Such "scaffolding" can change at any point in a person's life making them extremely vulnerable to rapid and substantial deteriorations in their coping abilities. The need for specialist Community Brain Injury Services that provide neuro-rehabilitation, including psychotherapeutic services, in the long-term, is therefore well illustrated by this case study (Tyerman \& King, 2008).

Fourth, Judith's case helpfully demonstrates that emotional growth and positive psychotherapeutic outcome are possible in these types of very challenging circumstances. The case suggests that cognitive rehabilitation and broad social support networks may be required, in addition to the psychological interventions, for this to occur. The importance of services providing support to the "supporters" of such clients is therefore also implied by the case. 
Fifth, the authors rightly question whether a PTSD diagnosis in Judith's case was appropriate, and they correctly, in my opinion, suggest that it was not. In the absence of such a diagnosis, I think the likelihood of any traumatic preservation occurring, as was described in my case of FS (King, 2002), is substantially reduced (King, 2002). By drawing attention to the case of FS, however, Ward and Hogan helpfully remind the reader that psychotherapeutic encounters are not necessarily without significant risks of harm in some circumstances. They also remind clinicians that they should be continually mindful of working within their own psychotherapeutic and neuropsychological competences. The implication would appear to be that in the kinds of situations highlighted by the case study of Judith, an awareness of when cases should be referred on to services with specialist neuropsychological expertise or when specialist psychotherapeutic /neuropsychological supervision should be sought are vitally important.

All of the above issues can be easily overlooked when providing psychotherapeutic services to people with neuropsychological impairment, and the case of Judith very helpfully highlights their importance.

\section{LIMITATIONS IN WHAT THE CASE OF JUDITH DEMONSTRATES}

While these salient issues are raised by this case, there are, however, a number of quite fundamental ways in which it may not have optimally demonstrated them:

First, the authors report that they have previous experience of working with neurologically impaired patients and give the example of their work with people with a diagnosis of chronic fatigue syndrome/Myalgic Encephalopathy [ME]. However, many clinicians would not share their view that the impairments caused by this condition have an organic basis, and therefore would question whether such experience has direct relevance to working with someone with a severe head injury where the presence of impairments caused by neuropathology is unequivocal.

Second, there is insufficient clinical data to determine whether Judith actually sustained a severe brain injury or not. On one hand, "a moderate head injury" with a short period of unconsciousness caused by a "glancing blow to the head" might indicate a mild to moderate traumatic brain injury. Such an injury would not normally be associated with any permanent neurological damage. On the other hand, a possible post-traumatic amnesia of 12 weeks and the reports of behaviors that might be consistent with very severe executive impairments (e.g., taking many hours to make packed lunches) would be consistent with a very severe head injury. Without additional clinical data it is difficult to be sure of the severity of Judith's traumatic brain injury and the extent to which her persisting sequelae can be attributed to organic and/or psychological factors.

Third, without a full neuropsychological assessment it is difficult to be certain that executive impairments existed and/or that they best accounted for her apparent cognitive and behavioral difficulties. The reports of "executive difficulties" at 12 weeks post-injury from a "psychological assessment” and the administration of three WAIS III subtests at the time of 
N. King

Complexities and Issues Raised by the Case of "Judith"

Pragmatic Case Studies in Psychotherapy, http://pcsp.libraries.rutgers.edu

Volume 11, Module 1, Article 2, pp. 21-25, 03-01-15 [copyright by author]

treatment are insufficient to confirm the existence of executive impairment. A large range of other neuropsychological hypotheses might account for Judith's presenting difficulties, which could only be verified by a full neuropsychological assessment.

Fourth, even if objective evidence of executive impairments was demonstrated, it would not necessarily follow that these were best explained by any neuropathology, as opposed to other factors like depression, anxiety, or chronic fatigue.. A skeptic could therefore claim that the case may have merely described a woman who sustained a mild to moderate head injury without any long-term neuropathology or executive impairment, whose day-to-day difficulties were mainly manifestations of depression, demotivation and/or chronic fatigue; and that these were erroneously hypothesized to be due to executive impairment arising from neuropathology that was not in fact present.

Finally, the significant limitations of solely using client-centered psychological approaches for neurologically impaired clients are not fully addressed in the paper. Many clients in such positions need specialist "neuropsychotherapy" (Prigatano, 1986), and this could have been stressed more in the case study in my opinion. These approaches emphasize the importance of helping the client understand neurological and neuropsychological elements of their condition to make sense of their brain injury, set realistic goals for their future, and explore/accept new aspects of their identity (Prigatano, 1986). Client-centered principles are therefore always essential for such clients, but are often not sufficient in themselves for optimal psychotherapeutic efficacy.

Overall, even though as outlined above I believe there are some conclusions in Ward and Hogan's case study of Judith that are not fully demonstrated by it, they are to be commended for showing the richness and complexity contained within a single neuropsychological case.

\section{REFERENCES}

Gracey, F., Palmer, S., \& Ross, B. (2008). “Feeling Part of Things”: Personal construction of self after brain injury. Neuropsychological Rehabilitation, 18, 627-650.

King, N.S. (2002). Perseveration of traumatic re-experiencing in PTSD: A cautionary note regarding exposure based psychological treatments for PTSD when head injury and dysexecutive impairment are also present. Brain Injury, 16, 65-74.

Potter, S. \& Brown, R.G. (2012). Cognitive behavioural therapy and persistent postconcussional symptoms. Integrating conceptual issues and practical aspects of treatment. Neuropsychological Rehabilitation, 22, 1-25.

Prigatano, G.P. (1986). Psychotherapy after brain injury. In G.P. Prigatano (Ed.)., Neuropsychological rehabilitation after brain injury, 67-69. Baltimore: John Hopkins University Press.

Tyerman, A. \& King, N.S. (2012). Interventions for psychological problems after brain injury. In L.M. Goldstein \& J. McNeil (Eds.). Clinical neuropsychology: A practical guide to assessment and management for clinicians, $2^{\text {nd }}$ Edition, 522-548. Chichester: John Wiley. 
N. King

Complexities and Issues Raised by the Case of "J udith"

Pragmatic Case Studies in Psychotherapy, http://pcsp.libraries.rutgers.edu

Volume 11, Module 1, Article 2, pp. 21-25, 03-01-15 [copyright by author]

Tyerman, A. \& King, N.S. (2008). Community rehabilitation. In A. Tyermann \& N.S. King, (Eds.). Psychological approaches to rehabilitation after traumatic brain injury, 65-90. Oxford: Blackwell.

Ward, T., \& Hogan, K. (2015). Using client-centered psychotherapy embedded within a pluralistic integrative approach to help a client with executive dysfunction: The case of "Judith." Pragmatic Case Studies in Psychotherapy, 11(1), Article 1, 1-20. Available: http://hdl.rutgers.edu/1782.1/pcsp_journal

Whitehouse, A.M. (1994). Applications of cognitive therapy with survivors of head injury. Journal of Cognitive Psychotherapy: An International Quarterly, 8, 141-160. 